\title{
The CNC Machining Process Design and Programming of the Drive Shaft
}

\author{
Zhu Xiurong, Zhang Xin, Liu Yang and Sun Zhijie \\ College of Mechanical Engineering, Jilin Teacher's Institute of Engineering and \\ Technology, Changchun, Jilin, China 130052 \\ zxr67811@163.com
}

\begin{abstract}
This paper introduces in detail the main processing contents of the transmission shaft. At the same time, the processing characteristics of shaft parts were discussed, and the methods and steps of processing the machining process of shaft parts were analyzed. Processing scheme decision making, in accordance with the nature of the material, shape and position accuracy requirements, select the appropriate program, and then according to the surface roughness requirements, select the processing program. With the analysis of the shape and position precision and the surface roughness and the plan of the plan, the processing scheme is reasonable.
\end{abstract}

Keywords: Drive shaft; CNC machining; process design; Programming

\section{Introduction}

Manufacturing industry is the pillar industry of China's national economy, which accounts for more than $40 \%$ of China's GDP, and advanced manufacturing technology is an important part of the revitalization of the manufacturing system engineering. NC machining is the core technology, its appearance and brought the huge benefit to arouse the attention of world science and technology with industry. At present, CNC machine tool can plate processing, cover, box structure, the shaft and other parts. The output shaft is common turning parts. When turning on a shaft machining CNC machine bed and need to meet the machining accuracy and surface roughness requirements. Therefore, research on transmission shaft of $\mathrm{CNC}$ machining process design is very necessary.

Application of fuzzy reasoning technology in computer aided process planning (CAPP) mainly in the decision process, especially multi process scheme evaluation and decision, is more effective. Now to drive shaft machining features and typical processing scheme fuzzy mapping relations are discussed.

\section{CNC Machining Process Design of Transmission Shaft}

\subsection{Transmission Shaft Parts Diagram Analysis}

Drive shaft has two $\Phi 32$ outer circle shaft segments, middle is $\Phi 50$ Shaft section. So it belongs to the ladder shaft, There are steps in the middle. There is a routine keyway milling and flat milling, Drilling and cutting thread tanker. In addition, Drive shaft in terms of position requirements is: Shaft section $\Phi 50 \mathrm{n} 7$ the coaxial tolerance of the reference $\mathrm{A}$ is $\Phi 0.03$. Other no special requirements, it is processed according to the general axis parts processing.

The material of the shaft is made of steel 45 , Heat treatment for quenching and tempering220-250HB, No note fillet R1.5, No note Dimensional tolerance IT14 level. 
It can be seen from the drawing shaft of the processing content: there are two $\Phi 32 \mathrm{f7}$ outer circles, Ra1.6, one $\Phi 50 \mathrm{n} 7$ outer circle, Ra1.6. Processing has a higher accuracy requirements. the $\Phi 50 \mathrm{n} 7$ outer circle with respect to the reference A Coaxial tolerance is $\Phi 0.03$ Position accuracy is relatively high. groove, Chamfer $\mathrm{C} 2$ and thread It belongs to the general requirements, the processing time required to complete the semi finishing. The blind hole $\Phi 7$ deep 3. The through hole $\Phi 7$ and keyway (Surface roughness requirement is Ra3.2um) And four plane (surface roughness requirements for Ra3.2um), belonging to the precision requirement. It takes in after finishing CNC milling machine for processing. Transmission shaft overall accuracy requirements higher, process pay attention to three elements of cutting tool and the choice

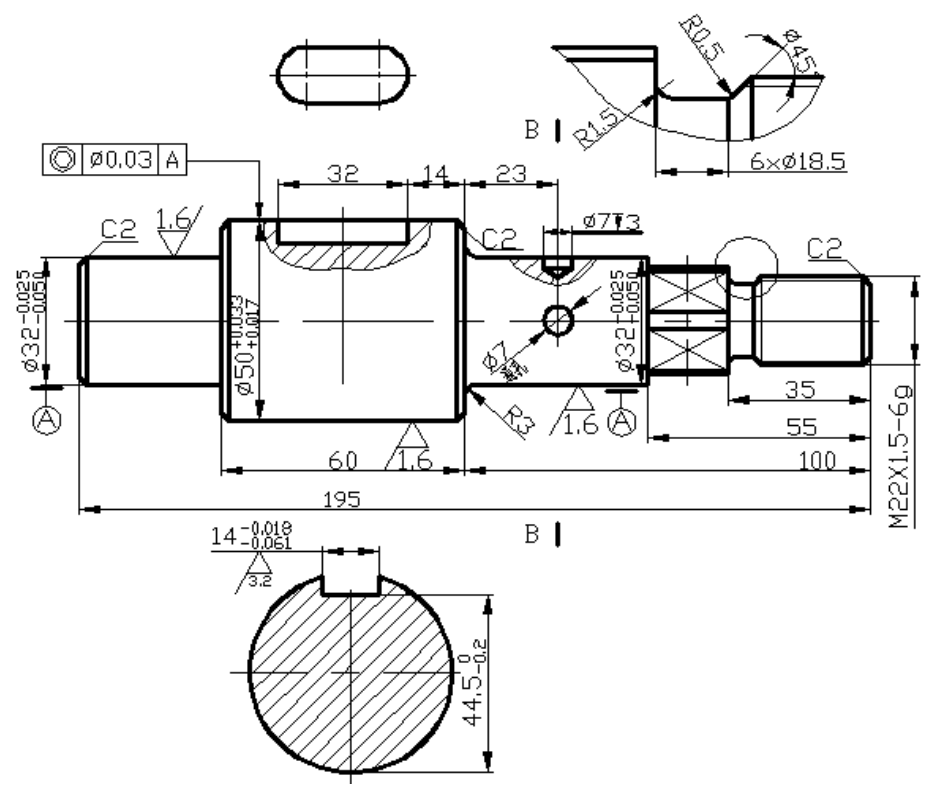

Figure 1. Drive Shaft Part Drawing

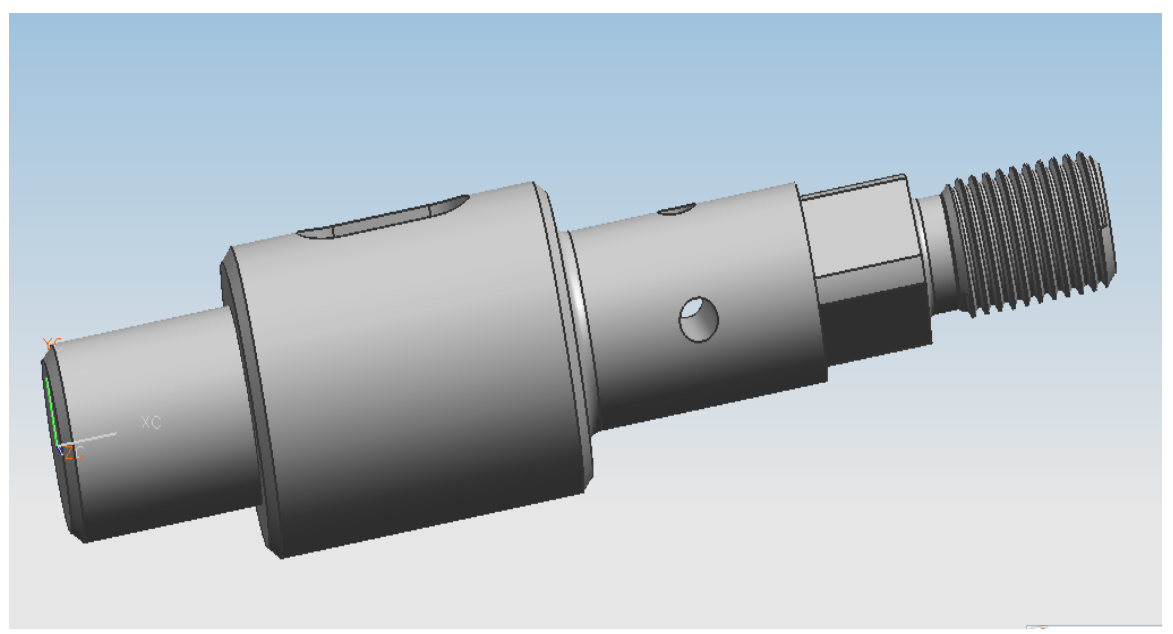

Figure 2. Three Dimensional Model of Transmission Shaft

\subsection{CNC Machining Process Analysis of Transmission Shaft}

1. Positioning mode and installation

Positioning benchmarks follow the principle of unity, positioning and design datum coincidence. So to improve the programming and numerical simulation in the simplicity and accuracy of determined the axis of the bar, playing center holes at the two ends of the 
shaft, with both ends of the center hole alternative ideal center line positioning processing. Clamping mode: left the three jaw self centering chuck clamping, the right end of the top tight clamping.

2. Determine the parts of the blank

Selection 45 bar (bar), the size of the blank under: $\phi 55 \times 200$.

3 . Determine the processing route

Processing according to the coarse to fine, from far and near to the principle of determined. Namely, the first from right to left for rough lathing, and from right to left to finish and semi finish lathing. When the rough to interior blunt down and chamfering, in semi finish lathing the completion of key slot and plane and again chamfer processing. And then finish machining. The driving shaft and the specific processing steps roughly as follows: first rough lathe $\phi 22, \phi 27, \phi 32, \phi 50$ outside circle; Second Semi finish machining $\phi 27, \phi 32, \phi 50$ outside circle. Grooving, Screw thread; Finish machining $\phi$ 32, $\phi 50$ outside circle; Keyway milling, plane milling; Last, drill the blind hole of $\phi$ 7 deep 3 and the through hole of $\phi 7$.

Table 1. Selection of Machine Tool

\begin{tabular}{|c|c|c|c|c|}
\hline No. & $\begin{array}{c}\text { Machine } \\
\text { Name }\end{array}$ & Processing contents & Model & Specifications \\
\hline 1 & Plain lathe & Rough lathe $\varphi 32, \varphi 50$ outer circle & CA6140 & $\Phi 400 \times 650$ \\
\hline 2 & CNC lathe & $\begin{array}{l}\text { Semi fine lathe and fine lathe } \Phi ~ 32, \Phi 50 \\
\text { outside circle, lathe M22X1.5-6g thread }\end{array}$ & CK3665 & $\Phi 360 \times 650$ \\
\hline 3 & $\begin{array}{c}\text { CNC milling } \\
\text { machine }\end{array}$ & $\begin{array}{l}\text { Milling keyway } \phi 14, \text { the blind hole of } \phi 7, \\
\text { the through hole of } \phi 7 \text { and the four plane }\end{array}$ & XD-40A & $\begin{array}{c}600 \times 520 \times \\
420\end{array}$ \\
\hline
\end{tabular}

\subsection{Selection of Transmission Shaft Machine Tool}

1. Lathe roughing operation selection of horizontal CA6140 ordinary lathe because rough machining should pay attention to the principle of separation of coarse fine, but also to take into account the requirements and efficiency, comprehensive above factors, the use of rough machining horizontal CA6140 ordinary lathe.

2. Semi precision lathe, precision machining selection CK3665 CNC lathe, because the semi precision and precision of the lathe allowance has been relatively small, and the accuracy requirements are relatively high, comprehensive above factors, so the semi finish machining precision machining selection CK3665 CNC lathe.

3. Milling choose FANUC 0i system XD40A vertical milling machine. Because the keyway milling, hole, the plane and machining parts more so when milling selection of FANUC 0i system XD40A vertical milling machine.

\subsection{Fixture Selection}

Clamping ways: to determine part axis for the locating datum. Machining contour to ensure an installation process the outer contour, needs the three jaw chuck is clamped on the left, right end of the left with a center hole and tailstock peaked tightly to improve the rigidity of the process system. Milling machine with a V type block and dividing head, such as positioning. Fixture selection are shown in Table 2. 
Table 2. Fixture Selection

\begin{tabular}{|c|l|l|l|}
\hline No. & \multicolumn{1}{|c|}{ Operation name } & model & Fixture name \\
\hline 1 & Rough lathe $\varphi 32, \varphi 50$ outer circle & CA6140 & Three jaw chuck, \\
thimble \\
\hline 2 & $\begin{array}{l}\text { Semi fine lathe } \Phi ~ 32, \Phi 50 \text { outside } \\
\text { circle, lathe M22X1.5-6g thread }\end{array}$ & CK3665 & \\
\hline 3 & Fine lathe $\Phi ~ 32, \Phi 50$ outside circle & CK3665 & \multirow{2}{*}{$\begin{array}{l}\text { V shape block, } \\
\text { dividing head }\end{array}$} \\
\hline 5 & Milling keyway $\Phi 14-0.018-0.061$ & XD-40A & \\
\hline 6 & Milling keyway $\Phi 14$, the blind hole & XD-40A & \\
\hline
\end{tabular}

\subsection{Specific Choice of Cutting Tools}

The content of shaft parts of the processing is mainly dominated by turning, and must be rough and finish machining separate, intermediate and semi finishing processes. Therefore, processing, the selection of the tool according to the different of the content of the processing, to meet the different requirements of the tool, general in the rough machining focus on efficiency of tool performance, and fine processing more emphasis on tool precision capability. First of all, we should understand the content of the processing, processing sequence and processing precision requirement, and then select the processing necessary tool. Here, There will be the $\phi 32$ and the $\varphi 50$ outer circle meanwhile finishing, should pay attention to is the need about partial knife. The specific choice of tool see Table 3.

Table 3. Specific Choice of Cutting Tools

\begin{tabular}{|c|c|c|c|c|c|}
\hline \multirow{3}{*}{ No. } & \multirow{3}{*}{ Operation name } & \multicolumn{4}{|c|}{ Machining method and tool selection } \\
\hline & & \multirow{2}{*}{$\begin{array}{l}\text { Machining } \\
\text { method }\end{array}$} & \multicolumn{3}{|c|}{ Tool content } \\
\hline & & & Tool Name & Specifications & Tool No. \\
\hline 1 & $\begin{array}{l}\text { The end face and } \\
\text { the Chamfer }\end{array}$ & Lathe & $45^{\circ}$ Turning tool & 16 & T01 \\
\hline 2 & The center hole & Drill & $\Phi 2$ Center drill & $A-2$ & T02 \\
\hline \multirow{3}{*}{3} & \multirow{3}{*}{$\begin{array}{c}\text { The } 2 \times \phi 32-0.025 \\
-0.050 \text { outer circle } \\
\text { Ra1.6 }\end{array}$} & Rough lathe & $90^{\circ}$ Turning tool & 20 & T03 \\
\hline & & Semi fine lathe & $93^{\circ}$ Turning tool & 22 & T04 \\
\hline & & fine lathe & $\begin{array}{l}\text { Left and right } \\
\text { offset knife }\end{array}$ & 22 & T05 \\
\hline \multirow{3}{*}{4} & \multirow{3}{*}{$\begin{array}{c}\text { The } \Phi 50+0.033 \\
+0.017 \text { outer circle } \\
\text { Ra1.6 }\end{array}$} & Rough lathe & $90^{\circ}$ Turning tool & 20 & T03 \\
\hline & & Semi fine lathe & $93^{\circ}$ Turning tool & 22 & T04 \\
\hline & & Fine lathe & $\begin{array}{l}\text { Left and right } \\
\text { offset knife }\end{array}$ & 22 & T05 \\
\hline 5 & $\begin{array}{c}\text { The M22X1.5-6g } \\
\text { thread }\end{array}$ & Lathe & $\begin{array}{l}\text { Thread lathe } \\
\text { tool }\end{array}$ & & T06 \\
\hline \multirow{2}{*}{6} & $\begin{array}{c}\text { The } \Phi \text { 14-0.018 - } \\
0.061 \text { keyway }\end{array}$ & Milling keyway & $\begin{array}{l}\text { Milling keyway } \\
\text { knife }\end{array}$ & A-5 & T07 \\
\hline & Four small plane & End milling & $\begin{array}{l}\text { End milling } \\
\text { knife }\end{array}$ & A-50 & T08 \\
\hline
\end{tabular}




\begin{tabular}{|c|c|c|c|c|c|}
\hline $\begin{array}{c}\text { The blind hole and } \\
\text { through hole of } \phi 7\end{array}$ & Drill hole & $\Phi 7$ drill & $\Phi 7$ & T09 \\
\hline
\end{tabular}

\subsection{Measuring Tool Selection}

Inspection is a part, precision of the outside dimension is in accordance with the requirements of the drawings, first of all, we should choose reasonable measuring. The so-called reasonable is refers to the selected measuring true, correct, effective measurement of the dimension accuracy of the parts. Usually measuring basis for:

1. Considering the measurement of parts of the site and the project. If parts have been measured and the aperture size should choose vernier caliper, inner micrometer or bore dial indicator.

2. Considering the accuracy of parts measurement (nominal dimensions and tolerances). In the choice of measuring tools, first of all, we should first see the dimension accuracy of the parts, smaller tolerances should select micrometer; tolerances is large, for the convenience of measurement, fast vernier caliper.

One of the options is to consider the economy of measurement. The same size can sometimes be achieved with different measuring tools.

Table 4. Measuring Tool Selection

\begin{tabular}{|c|c|c|c|c|}
\hline No. & $\begin{array}{l}\text { Processing content and Accuracy } \\
\text { requirements }\end{array}$ & Gage Name & Specifications & Accuracy \\
\hline \multirow{3}{*}{1} & \multirow{3}{*}{$\begin{array}{c}\text { The } \Phi 32-0.025-0.050 \text { and the } \\
\Phi 50+0.033+0.017 \text { outer circle Ra1.6 }\end{array}$} & Outside micrometer & $\begin{array}{l}50-75 \mathrm{~mm} / \\
25-50 \mathrm{~mm}\end{array}$ & $0.001 \mathrm{~mm}$ \\
\hline & & Vernier caliper & $0-200 \mathrm{~mm}$ & $0.02 \mathrm{~mm}$ \\
\hline & & $\begin{array}{c}\text { Surface roughness } \\
\text { tester }\end{array}$ & & \\
\hline 2 & The M22X1.5-6g thread & Thread pass check & & \\
\hline \multirow{2}{*}{3} & \multirow{2}{*}{ The $\Phi$ 14-0.018 -0.061 keyway } & Inside micrometer & $0-25 \mathrm{~mm}$ & $0.001 \mathrm{~mm}$ \\
\hline & & Depth micrometer & $0-25 \mathrm{~mm}$ & $0.001 \mathrm{~mm}$ \\
\hline 4 & $\begin{array}{l}\text { The blind hole and the through hole } \\
\text { of } \Phi 7 \text {, four small plane }\end{array}$ & Vernier caliper & $0-200 \mathrm{~mm}$ & $0.02 \mathrm{~mm}$ \\
\hline
\end{tabular}

\subsection{Selection of Cutting Parameter}

In the processing process, the need for a given amount of cutting( cutting depth, spindle speed and feed rate), so in the process must determine the CNC machining of three cutting factors. Under the selected tool wear degree, according to the instructions for use of CNC machine tools, processing material type is cast iron, steel or non-ferrous metals, etc.), processing requirements (roughing, semi finishing processing or finishing) and other technical requirements, and requires a combination of practical experience to determine the amount of cutting. At the same time, cutting parameters selection should also consider the dynamics of the machine tool stiffness, in order to adapt to the dynamic characteristics of the $\mathrm{CNC}$ machine tools should be high cutting speed and small amount of feed.

The principle of selection of cutting parameters is: to ensure the machining accuracy and surface roughness of the parts, to give full play to the performance of machine tools, to maximize production efficiency and reduce costs. 
The cutting speed $\mathrm{Vc}$ is converted into a speed formula as follows: $\mathrm{n}=1000 \mathrm{~V} \mathrm{c} / 3.14 \mathrm{~d}(\mathrm{r} / \mathrm{min})$

D-cutting surface diameter $(\mathrm{mm})$

Vc-cutting speed $\mathrm{m} / \mathrm{min}$

Table 5. Selection of Cutting Parameter

\begin{tabular}{|c|c|c|c|c|}
\hline \multirow[b]{2}{*}{ No. } & \multirow[b]{2}{*}{ Process contents } & \multicolumn{3}{|c|}{ Three elements of cutting } \\
\hline & & $\begin{array}{l}\text { Cutting depth } \\
(\mathrm{mm})\end{array}$ & $\begin{array}{l}\text { Feed rate } \\
(\mathrm{mm} / \mathrm{r})\end{array}$ & $\begin{array}{c}\text { Cutting speed } \\
(\mathrm{m} / \mathrm{min})\end{array}$ \\
\hline 1 & Rough lathe $\phi 22, \Phi 27, \Phi 32$ outer circle & 1.5 & 0.4 & 110 \\
\hline 2 & Rough lathe $\Phi 32, \Phi 50$ outer circle & 1.5 & 0.4 & 110 \\
\hline 3 & Semi fine lathe $\Phi 32$ outer circle & 0.5 & 0.2 & 132 \\
\hline 4 & lathe thread & & & 80 \\
\hline 5 & Semi fine lathe $\phi 27, \Phi 32, \Phi 50$ outer circle & 0.5 & 0.2 & 132 \\
\hline 7 & fine lathe $\phi 32, \phi 50$ outer circle & 0.2 & 0.1 & 150 \\
\hline 6 & fine lathe $\phi 32$ outer circle & 0.2 & 0.1 & 150 \\
\hline 8 & Milling keyway & 2.75 & 0.3 & 120 \\
\hline 9 & Milling plane & 2.5 & 0.3 & 120 \\
\hline 10 & drill the blind hole and through hole of $\phi 7$ & 7 & 0.15 & 16 \\
\hline
\end{tabular}

\section{Preparation of the Drive Shaft CNC Machining Process Card}

\subsection{Shaft CNC Machining Process Card Production}

The CNC machining process card is a kind of process document that the process is a unit to explain parts machining process. It briefly process picture, is the foundation for formulating other process documents. This kind of card to each working procedure stipulation and the description is not concrete, therefore in mass production and mass production in general can not know the worker operation, but many as the production management numerical control processing use, Need to prepare the CNC machining process card, to guide the operator. But in a small batch production, usually no longer the preparation of a more detailed process files, it can directly guide the production, to guide the operation of workers.. In this case, the transmission shaft of CNC machining process card preparation and preparation of CNC machining process card, as shown in Table 6. The table is the transmission shaft $\mathrm{CNC}$ machining process card. You can use the computer aided process design for the preparation.

Table 6. CNC Machining Process Card of Drive Shaft

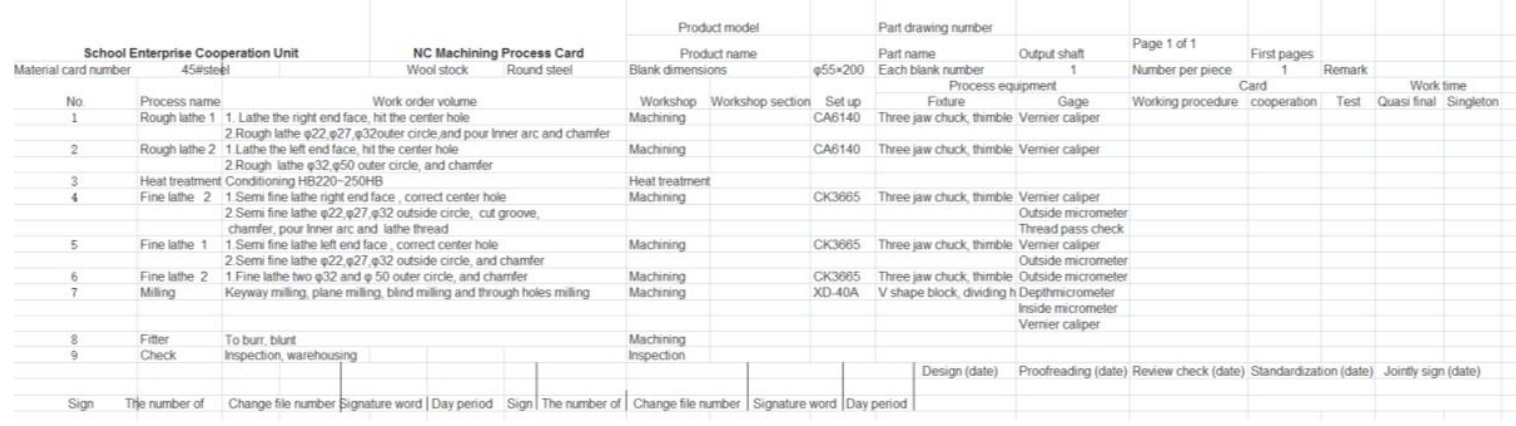




\subsection{Programming}

FANUC 0i Mate-TD system
01005
N010 G54 G99 G21
N012 T0101
N013 M03 S1200
N014 G00 X60. 0 Z5. 0
N016 G71 U1. 5 R1. 0
N018 G71 P020 Q032 U0. 5 W0. 3

F0. 3

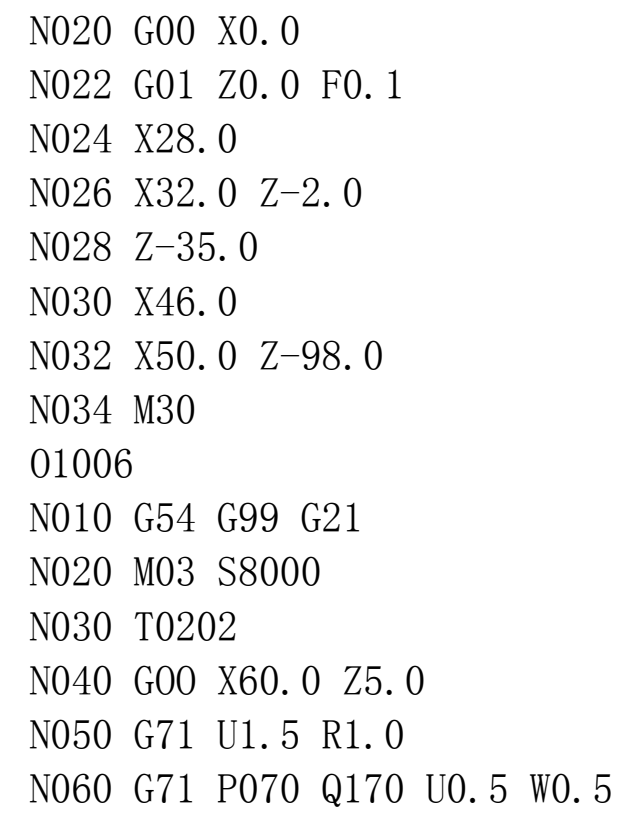

F0. 2

$$
\begin{aligned}
& \text { N070 G00 X0.0 } \\
& \text { N080 G01 Z0.0 F0. } 1 \\
& \text { N090 X18. } 0 \\
& \text { N100 X21. } 8 \text { Z-2.0 } \\
& \text { N110 Z-37. } 0 \\
& \text { N120 X31.0 } \\
& \text { N130 Z-55.0 } \\
& \text { N140 X32.0 Z-97. } 0
\end{aligned}
$$

\author{
N150 G02 X38. 0 Z-100. 0 R3. 0 \\ N160 G01 X46. 0 \\ N170 X50. 0 Z-102. 0 \\ N180 G00 X100. 0 Z100. 0 \\ N182 M05 \\ N190 M00 \\ N200 M03 S1500 \\ N202 G00 X60. 0 Z5. 0 \\ N204 G70 P070 Q170 \\ N206 G00 X100. 0 Z100. 0 \\ N210 T0303 \\ N212 M03 S500 \\ N220 G00 X60. 0 Z60. 0 \\ N230 G75 R0. 5 \\ N240 G75 X18. 5 Z-35. 0 P0 Q0 \\ F0. 05 \\ N250 G00 X100. 0 Z100. 0 \\ N260 M05 \\ N262 M00 \\ N270 M03 S600 \\ N280 T0404 \\ N290 G00 X30. 0 Z4. 0 F1. 5 \\ N300 G92 X21. 5 Z-33. 0 \\ N310 X20. 7 \\ N320 X20. 1 \\ N330 X19. 8 \\ N340 X19. 7 \\ N350 X19. 6 \\ N360 X19. 5 \\ N370 X19. 5 \\ N390 G00 X100. 0 Z100. 0 \\ N400 M30
}

\section{Concluding Remarks}

In this paper, the technical requirements of the transmission shaft $\mathrm{NC}$ machining process design, parts of the material and blank forms are briefly introduced. The precision, performance and service life of the machine are directly influenced by the machining quality of shaft parts. The main contents of the shaft are introduced in detail-- lathing and milling, At the same time, the process characteristics of the parts were described, the method and the steps of making the part machining process are also analyzed. Requires lathe the end face, lathe outside circle, cutting groove, lathe thread and other processes. The parts both in shape and size precision or accuracy of form and position are considered 
relatively simple one, but it also has unique is refined processing required about partial knife, but parts of the shape is ladder type, processing milling keyway, milling plane. It can be processed according to general shaft parts of the processing. When making decision, according to the properties of the material, the shape and the position accuracy, the choice of the appropriate plan, and then according to the surface roughness requirements, select the processing plan.

\section{References}

[1] S. Song, "Numerical Control Machining Technology", Electronic Science Publishing House, Beijing. (2008).

[2] X. Zhao and J. Cheng, "Numerical Control Processing Technology and Programming", Publishing House of electronics industry, BeiJing, (2010).

[3] K. Wang and J. Feng, "Selection of Cutting Tools and Determination of Cutting Parameters", Journal of Changsha Aeronautical Vocational and Technical College, vol. 8, no. 3, (2008), pp. 65-67

[4] G. Wu, "Analysis of Positioning in Machining Datum of the Selection and Application of Chinese Journal", no. 1, (2011), pp. 58.

[5] K. Wang and J. Feng, "High Efficiency Machining Technology for Large Forgings", Journal of Harbin University of Science and Technology, no. 2, (2013), pp. 65-67.

[6] Y. Cheng, L. Liu, J. Qian, Y. Gong and H. Shi, "Automotive Panel Die Machining Technology of Hardened Steel”, Journal of Harbin University of Science and Technology., no. 2, (2013), pp. 13-15

[7] H. Song and F. Yang, "Numerical Control Processing Technology", Mechanical Industry Press, Beijing, (2010).

[8] D.Lu, "Research and Development of Intelligent Programming System For NC Machining Based on Template", Huazhong University of Science and Technology, WuHan, China, (2011).

[9] L. Xu, "Research on Process Decision Making and Cutting Parameters in NC Machining", Shenyang University of Technology, Shenyang, China, (2006).

[10] L. Zhao and S. Zhang, "Computer Aided Process Design”, Mechanical Industry Press, Beijing, (2014). 